\title{
Respiratory effects of diazepam/methadone combination in rats: a study based on concentration/effect relationships
}

\author{
Lucie Chevillard ${ }^{\mathrm{a}, *}$ \\ Xavier Declèves ${ }^{\mathrm{a}}$ \\ Frédéric J. Baud ${ }^{\mathrm{a}, \mathrm{b}}$ \\ Patricia Risède ${ }^{a}$ \\ Bruno Mégarbane $e^{\mathrm{a}, \mathrm{b}}$ \\ ${ }^{a}$ INSERM U705, CNRS UMR8206, Université Paris Descartes, Sorbonne Paris Cité, Faculté de \\ Pharmacie, Neuropsychopharmacologie des addictions, Paris, France \\ ${ }^{b}$ Assistance Publique- Hôpitaux de Paris, Hôpital Lariboisière, Réanimation Médicale et Toxicologique, \\ Université Paris-Diderot, Paris, France
}

Short title: Methadone/diazepam combination

Correspondence to: Lucie Chevillard, Université Paris Descartes, Sorbonne Paris Cité, Faculté de Pharmacie, Neuropsychopharmacologie des addictions, 75006 Paris, France. E-mail: luciechevillard@gmail.com

\begin{abstract}
Abbreviations: ANOVA, analysis of variance; AUC, area under the curve; BZD, benzodiazepine; CYP, cytochrome P450; DZP, diazepam; EDDP, 2-ethylidene-1,5-dimethyl-3,3-diphenylpyrrolidine; $f$, respiratory frequency; HPLC/MS, high performance liquid chromatography-mass spectrometry; $\mathrm{LD}_{50}$, lethal dose 50\%; NADPH, nicotinamide adenine dinucleotide phosphate; $\mathrm{PaO}_{2}$, arterial oxygen partial pressure; $\mathrm{PaCO}_{2}$, arterial carbon dioxide partial pressure; $\mathrm{T}_{\mathrm{I}}$, inspiratory time; $\mathrm{T}_{\mathrm{E}}$, expiratory time; $\mathrm{T}_{\mathrm{TOT}}$, total respiratory time; $\mathrm{V}_{\mathrm{E}}$, minute volume; $\mathrm{V}_{\mathrm{T}}$, tidal volume.
\end{abstract}




\section{ABSTRACT}

Methadone may cause respiratory depression and fatalities. Concomitant use of benzodiazepines in methadone-treated patients for chronic pain or as maintenance therapy for opiate abuse is common. However, the exact contribution of benzodiazepines to methadone-induced respiratory toxicity remains debatable. We investigated the respiratory effects of the combination diazepam $(20 \mathrm{mg} / \mathrm{kg}) /$ methadone $(5$ $\mathrm{mg} / \mathrm{kg}$ ) in the rat, focusing on methadone concentration/effect relationships. Respiratory effects were studied using arterial blood gases and whole-body plethysmography. Plasma concentrations of both $R$ and $S$-methadone enantiomers were measured using high-performance liquid chiral chromatography coupled to mass spectrometry. To clarify mechanisms of diazepam/methadone interaction, methadone metabolism was investigated in vitro using rat liver microsomes. Diazepam/methadone co-administration significantly increased methadone-related effects on inspiratory time $(p<0.001)$ but did not significantly alter the other respiratory parameters when compared with methadone alone, despite significant increase in the area under the curve of plasma $R$-methadone concentrations measured during $240 \min (p<0.05)$. Diazepam/methadone co-incubation with microsomes in vitro resulted in a significant inhibition of methadone metabolism $(p<0.01)$, with 50\%-inhibitory diazepam concentrations of $25.02 \pm 0.18 \mu \mathrm{mol} / \mathrm{L}$ and $25.18 \pm 0.23 \mu \mathrm{mol} / \mathrm{L}$ for $R$ - and $S$-methadone, respectively. We concluded that co-administration of high-doses of diazepam and methadone in rats is not responsible for additional respiratory depression in comparison to methadone alone, despite significant metabolic interaction between the drugs. In humans, although our experimental data may suggest the relative safety of benzodiazepine/methadone coprescription, physicians should remain cautious as other underlying conditions may enhance this drugdrug interaction.

Keywords: Diazepam; effect/concentration relationships; metabolism; methadone; plethysmography; respiratory effects 


\section{Introduction}

Methadone, a full agonist opioid, is widely used as treatment for chronic pain and for maintenance therapy in heroin addicts (Cicero and Inciardi, 2005; Mattick et al., 2008). Marketed methadone is a racemic mixture, with $R$-methadone believed to account for most, if not all, of its therapeutic effects and $S$-methadone suspected of playing a significant role in its adverse reactions (Mitchell et al., 2004). In humans, methadone (6-dimethylamino-4,4-diphenyl-3-heptanone) is metabolized by multiple cytochrome P450 (CYP) isoforms including 3A4, 2B6, 2C19, 2C9, and 2D6 to 2-ethyl-1,5-dimethyl-3,3diphenylpyrrolidine (EDDP), an inactive primary metabolite (Iribarne et al., 1996), with the potential risk of significant drug-drug interactions.

A steep rise in recreational use of prescription opioids was observed during the past two decades, resulting in increased fatalities mainly in relation to methadone abuse (Paulozzi, 2006). Methadone is increasingly prescribed and, as a result of its increased availability to patients, adjunctively diverted to recreational or habitual opioid abusers (Cicero and Inciardi, 2005). To date, although representing less than $5 \%$ of prescribed opioids in the U.S., methadone has been implicated in one-third of opioid-related poisonings (Webster et al., 2011).

Circumstances of methadone poisonings include overdoses and drug-drug interactions. Benzodiazepines (BZDs) are commonly used by opioid abusers to reduce anxiety, reinforce opioid effects, and treat craving and withdrawal symptoms (Lintzeris and Nielsen, 2009). Prevalence of BZD use among methadone-maintained patients ranges from 50 to 70\% (Jones et al., 2012). Screening for BZDs was found to be positive in more than $85 \%$ of methadone-intoxicated patients admitted to the intensive care unit (Mégarbane et al., 2010). Among BZDs, diazepam is one of the most preferred, prescribed, and thus abused molecules (Bramness and Kornor, 2007; Iguchi et al., 1993).

The real contribution of BZDs to methadone-related respiratory toxicity and fatalities remains under debate (Häkkinen et al., 2012; Jones et al., 2012; Paulozzi et al., 2009). In rats, methadone has been shown to induce a dose-dependent increase in inspiratory time $\left(\mathrm{T}_{\mathrm{I}}\right)$ with an additional increase in expiratory time $\left(\mathrm{T}_{\mathrm{E}}\right)$ at elevated doses, resulting in respiratory acidosis and hypoxemia (Chevillard et al., 
2010; McCormick et al., 1984; White and Zagon, 1979). In contrast, BZDs were shown to weakly alter arterial blood gases, even at elevated doses (McCormick et al., 1984; Mégarbane et al., 2005; Nielsen and Taylor, 2005), while BZD pre-treatment reduced methadone's median lethal dose (Borron et al., 2002) and potentiated methadone-related respiratory depression (McCormick et al., 1984; Nielsen and Taylor 2005). A pharmacokinetic interaction between methadone and diazepam was suggested in rats, in relation to a non-competitive inhibition of methadone metabolism by diazepam (Liu et al., 1978; Spaulding et al., 1974). However, using human microsomes, diazepam appeared to be a weak competitive CYP3A4 inhibitor in vitro, questioning the clinical relevance of such metabolic interaction (Iribarne et al., 1997). Consistently, clinical investigations in methadone-treated patients ruled out significant pharmacokinetic interactions between diazepam and methadone (Pond et al., 1982; Preston et al., 1986).

Given the possible role of BZDs in methadone-related toxicity and concerns regarding the in vivo relevance of pharmacokinetic interaction between these drugs, we designed an experimental study to better quantify the respiratory effects resulting from diazepam/methadone interaction, aiming to analyze its mechanism and clarify the exact role of each methadone enantiomer.

\section{Experimental procedures}

\subsection{Animals}

Male Sprague-Dawley rats (Janvier, France) weighing between 250 and $350 \mathrm{~g}$ at the time of experimentation were used. Animals were housed for 5 days before experimentation in an environment maintained at $21 \pm 0.5^{\circ} \mathrm{C}$ with controlled humidity and a light-dark cycle (lights on between 08:00 and 20:00 h). Food and tap water were provided ad libitum. All experimental protocols used in this study were carried out within the ethical guidelines established by the National Institutes of Health, the French Minister of Agriculture, and the European Union Legislation. Protocols were approved by the local ethics committee for animal experimentation of Paris-Descartes University.

\subsection{Chemicals and drugs}


Methadone hydrochloride and diazepam were purchased from Francopia, France. Pooled male rat liver microsomes $(20 \mathrm{mg} / \mathrm{mL}$ in a $0.25 \mathrm{~mol} / \mathrm{L}$ sucrose solution) and nicotinamide adenine dinucleotide phosphate (NADPH) regenerating system were purchased from Becton Dickinson Gentest, Le Pont de Claix, France. All other chemicals were purchased from Sigma, Saint-Quentin Fallavier, France. Methadone was diluted in Tween- $20^{\circledR}$ and sterile water to obtain solutions of 16 and $0.1 \mathrm{mmol} / \mathrm{L}$, respectively. Diazepam was diluted in Tween $-20^{\circledR}$ and methanol to obtain solutions of 70 and $10 \mathrm{mmol} / \mathrm{L}$, respectively.

\subsection{Femoral artery catheterization}

The day before the study, animals were anesthetized with $70 \mathrm{mg} / \mathrm{kg}$ ketamine (Ketalar ${ }^{\circledR}$ ) and 10 $\mathrm{mg} / \mathrm{kg}$ xylazine $\left(\right.$ Rompum $^{\circledR}$ ) intraperitoneally (i.p.) then placed on a warming blanket with regulating thermostat.. The femoral artery was catheterized using $30 \mathrm{~cm}$-silastic tubing with external and internal diameters of 0.94 and $0.51 \mathrm{~mm}$, respectively (Dow Corning Co., Midland, MI). Arterial catheters were tunneled subcutaneously (s.c.) and fixed at the back of the neck. Heparinized saline was injected into the catheter to avoid thrombosis and catheter obstruction. Rats were then returned to their individual cages for a minimum recovery period of $24 \mathrm{~h}$, to allow complete anesthesia washout. Moreover, ketamine/xylazine combination, routinely used for short surgical procedures, was chosen based on drug's short elimination half-lives to avoid any further significant interaction on ventilation with the investigated drugs tested $24 \mathrm{~h}$ later.

On the day of experimentation, rats were placed in horizontal Plexiglas cylinders $(6.5 \mathrm{~cm}$-internal diameter, up to $20 \mathrm{~cm}$-adjustable length) (Harvard Apparatus, Inc. Holliston, MA, USA), modified by the

addition of several holes at the cephalic end to avoid $\mathrm{CO}_{2}$ rebreathing (Chevillard et al., 2010). Before drug administration, the catheter was exteriorized, purged, and its permeability verified.

\subsection{Clinical findings}


Sedation level based on a 4-stage scale from 0 (awake) to 3 (coma) was assessed. At stage 0 , rats were completely awake and their gait and righting reflexes were intact. At stage 1, rats had reduced activity, showed light impairment of gait and an intact righting reflex with diminished muscular tonus. At stage 2, rats were asleep or static and showed a reduced righting reflex. At stage 3, rats were comatose and did not have any righting reflex. Temperature was measured using i.p. implanted temperature transmitters for the purpose of plethysmography study.

\subsection{Arterial blood gas study}

In catheterized rats, $100 \mu \mathrm{L}$-arterial blood samples were collected before (T0), and at 5, 10, 15, 30, $60,120,180$, and $240 \mathrm{~min}$ after i.p. injection of methadone or its solvent. Samples were immediately analyzed using Rapidlab $248^{\circledR}$ (Siemens Healthcare Diagnostics, Saint Denis, France). Every hour, 1000 $\mu \mathrm{L}$ heparinized $0.9 \% \mathrm{NaCl}$ was administered to the rat via the arterial catheter to reduce the risk of catheter clotting and to compensate for volume losses. Rats were subsequently euthanized using a carbon dioxide chamber.

\subsection{Whole body plethysmography}

Four days before the study, temperature transmitters (DSI, Chatillon, France) were implanted in the peritoneal cavity. Rats were then returned to their individual cages for a $72 \mathrm{~h}$-recovery period. Ventilatory parameters were recorded in a whole-body plethysmograph by the barometric method described and validated in the rat (Bartlett and Tenney, 1970). On the day of experimentation, animals were placed in a rectangular Plexiglas chamber with a 3 L-volume connected to a reference chamber of the same size by a high-resistance leak to minimize the effect of pressure changes in the experimentation room. The animal chamber was flushed continuously with humidified air at a rate of $5 \mathrm{~L} / \mathrm{min}$. During the recording periods, the inlet and outlet tubes were temporarily clamped and pressure changes associated with each breath were recorded using a differential pressure transducer (Validyne MP, $45 \pm 3 \mathrm{~cm} \mathrm{H}_{2} \mathrm{O}$, Northridge, CA), connected to the animal and reference chambers. During each measurement, calibration was performed by 
three injections of $1 \mathrm{~mL}$ of air into the chamber and the ambient temperature was noted. The spirogram was recorded and stored on a computer with an acquisition data card (PCI-DAS 1000, Dipsi, Chatillon, France) using respiratory acquisition software (Acquis1 Software, CNRS, Gif-sur-Yvette, France) for offline analysis.

This technique was daily validated with a series of leak tests (leak was signaled if diminution of the signal amplitude exceeded 33\% in $5 \mathrm{~s}$ ) (Bonora et al., 2004). The quantification threshold corresponded to a minimum air volume injection of $30 \mu \mathrm{l}$. Within the range of tested volumes (0.1 to $3 \mathrm{~mL})$, measurement was linear. The mean coefficient of intra-day variability (four series of five measurements carried out the same day) was $1.32 \pm 0.18 \%$. The mean coefficient of inter-day variability ( 25 measurements carried out on three different days) was $1.69 \pm 0.11 \%$. We checked that the mean $\mathrm{CO}_{2}$ measured using an Ohmeda 5250 RGM capnograph (rebreathing test) during clamping periods did not exceed $0.6 \%$ of the air contained in the chamber.

Before each measurement, the temperature of the enclosure, the temperature of the animal, the volume of calibration and the atmospheric pressure were noted to permit calculation of plethysmography parameters. The first measurement was performed after a 30-60 min-period of accommodation of the animal in the plethysmography unit. During this period, the rat was quiet and not in deep or rapid eye movement sleep which could be roughly estimated from its behavior, response to noise, and breathing pattern. Then, the rat was gently removed from the chamber for i.p. injection, and replaced in the chamber for the remaining measurements. Ventilation was recorded at 5, 10, 15, 30, and then every 60 min during four hours, each record lasting about $60 \mathrm{~s}$. The following parameters were determined using a specific formula (Bartlett and Tenney, 1970): tidal volume $\left(\mathrm{V}_{\mathrm{T}}\right), \mathrm{T}_{\mathrm{I}}$, and $\mathrm{T}_{\mathrm{E}}$. Additional parameters were calculated: the respiratory cycle duration $\left(\mathrm{T}_{\mathrm{TOT}}=\mathrm{T}_{\mathrm{I}}+\mathrm{T}_{\mathrm{E}}\right)$, the respiratory frequency $(f)$, and the minute volume $\left(\mathrm{V}_{\mathrm{E}}=\mathrm{V}_{\mathrm{T}} \times f\right)$. At the end of experimentation, rats were euthanized using a carbon dioxide chamber.

\subsection{In vitro study of methadone metabolism using liver microsomes}


Methadone metabolism by rat liver microsomes was studied in vitro as previously described (Cho et al., 1990). The incubation mixture consisted in $0.98 \mathrm{~mL}$ of $0.1 \mathrm{~mol} / \mathrm{L}$ HEPES buffer, $\mathrm{pH} 7.6$ containing NADPH regenerating system (1.3 mmol/L NADP, $3.3 \mathrm{mmol} / \mathrm{L}$ glucose-6-phosphate, $3.3 \mathrm{mmol} / \mathrm{L} \mathrm{MgCl}_{2}$, $0.4 \mathrm{IU} / \mathrm{mL}$ glucose-6-phosphate dehydrogenase) and $1 \mathrm{mg} / \mathrm{ml}$ rat microsomal protein. This mixture was pre-incubated for $15 \mathrm{~min}$ at $37^{\circ} \mathrm{C}$, and reactions were initiated by adding methadone at $1 \mu \mathrm{mol} / \mathrm{L}$, the minimal concentration we previously obtained in plasma between 5 and 240 min after i.p. administration of $5 \mathrm{mg} / \mathrm{kg}$ methadone to rats (Chevillard et al., 2010). To study the inhibition of methadone metabolism by diazepam, increasing concentrations of diazepam were added. For the in vitro time-course of methadone metabolism, aliquots $(100 \mu \mathrm{L})$ were removed from this mixture at $0,15,30,60$, and $120 \mathrm{~min}$. To study the inhibition of methadone metabolism by diazepam, aliquots were removed at 0 and $120 \mathrm{~min}$. The reaction was stopped by adding an equal volume of cold methanol. The reaction mixture was centrifuged at $10,000 \mathrm{~g}$ for $10 \mathrm{~min}$, and supernatants stored at $-80{ }^{\circ} \mathrm{C}$ until analyzed. Concentrations of methadone enantiomers and EDDP were measured in supernatants using liquid chromatography-mass spectrometry (HPLC/MS), without liquid phase extraction (see below). An aliquot of each supernatant


directly injected into the system. Triplicate samples were used in all the inhibition experiments.

\subsection{HPLC/MS determination of $R$ - and S-methadone and EDDP}

Samples were collected in catheterized rats concomitantly to those dedicated for arterial blood gas analysis. Three hundred microliters of blood were obtained from the arterial catheter before (T0), and at $5,10,15,30,60,120,180$, and 240 min after i.p. administration of methadone or its solvent. Samples were placed in Eppendorf tubes and centrifuged at 3,500 g for $10 \mathrm{~min}$. Subsequently, plasma (about 200 $\mu \mathrm{l})$ was separated and refrigerated at $-20^{\circ} \mathrm{C}$, until liquid-liquid extraction in Toxitubes $\mathrm{A}^{\circledR}$ (Varian, USA) and quantification using a specific HPLC/MS assay.

Analyses were performed on a ThermoFinnigan ${ }^{\circledR}$ liquid chromatograph/ion trap mass spectrometer LCQ Advantage ${ }^{\circledR}$, including a Surveyor ${ }^{\circledR}$ HPLC system which consisted of a degasser, a binary pump, 
and an autosampler. Chromatographic separation was carried out on a Cyclobond ${ }^{\circledR}$ I-2000 HP-RSP chiral column $(250 \mathrm{~mm} \times 4.6 \mathrm{~mm}$ I.D., $5 \mu \mathrm{m}$, Thermo Electron Corporation, Waltham, MA). Single ion storage detection was performed $(\mathrm{m} / \mathrm{z}((R$ and $S)$-methadone $)=310.1, \mathrm{~m} / \mathrm{z}(\mathrm{EDDP})=278.2) . R$-methadone, $S$ methadone, and racemic EDDP concentrations were calculated using the peak area ratios between the compound and its corresponding internal standard, i.e. deuterated racemic methadone $[(R, S)$-methadone$\mathrm{d}_{3}$ ] or deuterated EDDP [EDDP- $\mathrm{d}_{3}$ ], which was added before extraction at $5 \mu \mathrm{mol} / \mathrm{l}(20 \mu \mathrm{L})$. Limits of quantification were $3 \mathrm{nmol} / \mathrm{L}$ for both $R$ - and $S$-methadone enantiomers and $36 \mathrm{nmol} / \mathrm{L}$ for EDDP, with coefficients of variation of $15.8 \%, 13.5 \%$, and $10.8 \%$, respectively.

\subsection{Study designs:}

\subsubsection{In vivo study of diazepam/methadone combination}

Rats were randomized into four groups $(\mathrm{N}=8)$ and treated consecutively with s.c. $20 \mathrm{mg} / \mathrm{kg}$ diazepam + i.p. $5 \mathrm{mg} / \mathrm{kg}$ methadone (diazepam/methadone group), s.c. Tween-20 ${ }^{\circledR}+$ i.p. $5 \mathrm{mg} / \mathrm{kg}$ methadone (methadone group), s.c. $20 \mathrm{mg} / \mathrm{kg}$ diazepam + i.p. Tween- $20^{\circledR}$ (diazepam group), and s.c. Tween-20 ${ }^{\circledR}+$ i.p. Tween-20 ${ }^{\circledR}$ (solvent group). Subsequently, ventilation at rest was studied using arterial blood gas analysis and plethysmography. Plasma concentrations of both methadone enantiomers were measured at each sampling time. We investigated methadone/effects relationships regarding $\mathrm{T}_{\mathrm{I}}$ (the hallmark of opioid respiratory effects) and $\mathrm{PaCO}_{2}$ (the hallmark of respiratory depression) (Chevillard et al., 2009). Methadone $(5 \mathrm{mg} / \mathrm{kg})$ and diazepam $(20 \mathrm{mg} / \mathrm{kg})$ doses and routes of administration were those previously used in rats to assess methadone/diazepam interactions (McCormick et al., 1984; Nielsen and Taylor, 2005). Both drug doses can be considered as elevated doses, taking into account the lethal doses-50\% $\left(\mathrm{LD}_{50}\right)$, i.e. $18 \mathrm{mg} / \mathrm{kg}$ for i.p. methadone (Lynch and Meyers, 1958) and $32 \mathrm{mg} / \mathrm{kg}$ for intravenous diazepam (Pfizer, 2009).

\subsubsection{In vitro study of diazepam-related effects on methadone metabolism}


We studied the effects of 0 (control group), 25, 50, and $75 \mu \mathrm{mol} / \mathrm{L}$ diazepam on methadone metabolism $(1 \mu \mathrm{mol} / \mathrm{L})$. The dose range of diazepam was used in accordance with the value of the inhibition constant reported with human microsomes $\left(K_{I}=50 \mu \mathrm{mol} / \mathrm{L}\right.$; Iribarne et al., 1997).

\subsection{Statistical analysis}

Results were expressed as mean \pm S.E.M. For plethysmography, T0 was the mean of the three baseline measurements. To permit simultaneous analysis of the effect of time and various treatments, we calculated for each animal and for each studied parameter, the area under the curve (AUC) from T0 to the completion of the measurement (240 min) using the trapezoid method (Tallarida and Murray, 1984). For each measurement, we compared the baseline values, the values at each sampling time, and the AUCs. Noncompartmental analysis (WinNonlin version 5.1, Pharsight Corp, Mountain View, CA) was used to calculate methadone terminal elimination half-life $\left(\mathrm{T}_{1 / 2 \beta}\right)$ as well as the AUC from 0 to $240\left(\mathrm{AUC}_{0 \rightarrow 240}\right)$ and the percentage of extrapolation of the $\mathrm{AUC}$ from 0 to infinity $\left(\mathrm{AUC}_{0 \rightarrow \infty}\right)$ regarding methadone concentrations. We used Mann-Whitney $U$-tests for comparisons between two groups and two-way analyses of variance (ANOVA) followed by multiple comparison tests using Bonferroni's correction for comparisons between more than two groups. For the in vitro inhibition study, the 50\%-inhibitory diazepam concentration $\left(\mathrm{IC}_{50}\right)$ was determined for each enantiomer based on the metabolism inhibition curves using nonlinear regression. Inhibition of methadone metabolism was determined for each enantiomer as the relative difference in its concentrations between 0 and $120 \mathrm{~min}$ in the reaction aliquot. EDDP formation was determined as the relative difference in its concentrations between 0 and $120 \mathrm{~min}$ in the reaction aliquot. These variables were compared using one-way ANOVA followed by multiple comparison tests with Dunnett's correction. The concentration-effect relationships were analyzed using linear regression. All tests were performed using Prism version 4.0 (GraphPad Software, Inc., San Diego, CA), and $p$-values of less than 0.05 were considered significant.

\section{Results}




\subsection{In vivo study of diazepam/methadone combination's effects on ventilation}

Rats were free of symptoms in the diazepam group in comparison to the solvent group. In contrast, they were significantly sedated in the methadone and diazepam/methadone groups in comparison to the solvent and diazepam groups $(p<0.001$, Fig. 1). Interestingly, no significant differences were observed in sedation between the methadone and diazepam/methadone groups, while these groups significantly differed regarding body temperature $(p<0.01)$.

Regarding blood gases and plethysmography, no significant differences between baseline values were observed for each parameter between the groups. Methadone administration $(p<0.05)$ and diazepam/methadone co-administration $(p<0.01)$ were responsible for a significant decrease in $\mathrm{PaO}_{2}$ when compared to the solvent and diazepam groups. Similarly, diazepam/methadone co-administration was responsible for a significant decrease in arterial $\mathrm{pH}$ when compared to the solvent $(p<0.05)$ and diazepam groups $(p<0.001)$. Interestingly, none of the blood gas parameters significantly differed between the methadone and diazepam/methadone groups (Fig. 2).

Using AUC measurements, only $\mathrm{T}_{\mathrm{I}}$ was significantly increased in the diazepam/methadone group in comparison to the solvent, diazepam, and methadone groups $(p<0.001$, Fig. 3A). No significant differences regarding $f, \mathrm{~T}_{\mathrm{E}}$, and $\mathrm{V}_{\mathrm{T}}$ were observed between the methadone and diazepam/methadone groups. However, in the diazepam/methadone group, $\mathrm{T}_{\mathrm{I}}$ was significantly increased at 120 and $180 \mathrm{~min}(p$ $<0.05)$ and $\mathrm{T}_{\mathrm{E}}$ at $30(p<0.05), 60(p<0.01), 120(p<0.05)$, and $180 \mathrm{~min}(p<0.01)$, in comparison to the methadone group (Fig. 3B). Regarding $f$, a significant difference was measured at 120 min between the diazepam/methadone and the methadone group $(p<0.05)$.

\subsection{In vivo study of diazepam/methadone combination's effects on methadone concentrations}

Diazepam/methadone co-administration resulted in a significant increase in plasma $R$-methadone concentrations at $120(p<0.01), 180(p<0.01)$, and $240 \mathrm{~min}(p<0.001)$, without any significant modification in S-methadone concentrations (Fig. 4). Using the AUC method, there was a 2.0-fold increase in plasma $R$-methadone concentrations in relation to diazepam co-administration $(p<0.01)$, 
whereas plasma $S$-methadone concentrations were not significantly altered (1.5-fold increase). Regarding $\mathrm{T}_{\max }$ and $\mathrm{C}_{\max }$ of $R$-methadone, no significant differences were observed between the two groups. In rats treated with diazepam/methadone combination, neither $R$-methadone $\mathrm{T}_{1 / 2 \beta}(155.1$ versus $155.5 \mathrm{~min})$ nor $S$-methadone $\mathrm{T}_{1 / 2 \beta}(131.3$ versus $158.3 \mathrm{~min})$ was altered in comparison to rats treated with methadone alone.

\subsection{Analysis of methadone-related concentration/effect relationships}

We studied the relationships between methadone-induced respiratory effects (i.e. on $\mathrm{PaCO}_{2}$ and $\mathrm{T}_{\mathrm{I}}$ ) and plasma concentrations of the active $R$-methadone enantiomer, when $5 \mathrm{mg} / \mathrm{kg}$ methadone was administered alone or in combination with $20 \mathrm{mg} / \mathrm{kg}$ diazepam (Fig. 5). A clockwise hysteresis was observed for both parameters, whether diazepam was co-administered or not.

\subsection{In vitro study of diazepam-related effects on methadone metabolism}

No significant differences between the kinetics of $R$ - and $S$-methadone disappearance were observed. Diazepam co-incubation resulted in a dose-dependent decrease in $R$-and $S$-methadone concentrations in comparison to the control, however this was only significant with the two higher diazepam doses $(p<$ 0.01) (Fig. 6A). As a consequence of the inhibitory effect of diazepam on methadone metabolism, EDDP formation was significantly decreased for all diazepam doses (Fig. 6B). $\mathrm{IC}_{50}$ values of diazepam on $R$ and $S$-methadone metabolism were $25.02 \pm 0.18 \mu \mathrm{mol} / \mathrm{L}$ and $25.18 \pm 0.23 \mu \mathrm{mol} / \mathrm{L}$, respectively.

\section{Discussion and conclusions}

In rats, the diazepam/methadone combination does not significantly worsen methadone-induced respiratory effects despite a significant increase in plasma $R$-methadone attributed to diazepam-mediated inhibition of methadone metabolism, as assessed in vitro. 
Like any full mu-opioid receptor agonist, methadone-induced respiratory effects are characterized by a dose-related, naloxone-reversible depression of the resting total volume with a proportional reduction in $\mathrm{V}_{\mathrm{T}}$, decrease in $\mathrm{PaO}_{2}$ and arterial $\mathrm{pH}$, increase in $\mathrm{PaCO}_{2}$, and reduction in the ventilatory drive stimulated by hypercapnia (Shook et al., 1990). Previously, we showed that methadone increases $T_{I}$ in a dosedependent manner but only increases $\mathrm{T}_{\mathrm{E}}$ at elevated doses $(\sim 15 \mathrm{mg} / \mathrm{kg})$ resulting in respiratory depression (Chevillard et al., 2010).

Mechanisms and consequences of BZD/methadone interaction are debated in the literature (Jones et al., 2012). In mice, neither locomotor activity nor analgesia was altered when administering the diazepam/methadone combination in comparison to methadone alone (Shannon et al., 1976). In contrast, diazepam was reported to markedly potentiate methadone respiratory depressant effects when given in combination with methadone in rats (McCormick et al., 1984). The most severe respiratory depression occurred when both drugs were used together acutely, suggesting that the maximum deleterious effect occurred when concurrently used for the first time. Here, surprisingly, and although using the same doses and administration routes, only a significant increase in $\mathrm{T}_{\mathrm{I}}$ with a trend to a decrease in $\mathrm{PaO}_{2}$ was observed, suggesting limited deleterious effects on rat ventilation of the diazepam/methadone combination in comparison to methadone alone. It is noteworthy that in McCormick's study, diazepam was diluted in a solution containing $10 \%$ ethyl alcohol and $1.5 \%$ benzyl alcohol, and the interaction with methadone could have been responsible for the observed significant respiratory effects. Interestingly, the second animal study attributing deleterious respiratory effects using arterial blood gases to the diazepam/methadone combination, compared rats treated with a diazepam/methadone combination to rats treated with diazepam or solvent but not to rats treated with methadone alone (Nielsen and Taylor, 2005). These concerns question the exact respiratory consequences of the diazepam/methadone combination, as shown in our study.

As previously assessed with human microsomes (Iribarne et al., 1997), we confirmed the diazepammediated inhibition of methadone metabolism, using rat microsomes in vitro. Interestingly, our calculated diazepam $\mathrm{IC}_{50}(25.02 \mu \mathrm{mol} / \mathrm{L})$ was in the same range as the value reported by Iribarne et al. $(50 \mu \mathrm{mol} / \mathrm{L}$, 
Iribarne et al., 1997). Moreover, no differences in either the time-course of methadone disappearance or diazepam $\mathrm{IC}_{50}$ values for both methadone enantiomers were observed. Surprisingly, we found marked diazepam-induced inhibition of methadone metabolism into EDDP in vivo: AUCs of $R$ - and $S$-methadone were altered in rats treated with the diazepam/methadone combination but this was only significant for $R$ methadone, which suggested possible involvement in vivo of additional pathways in $S$-methadone clearance (i.e. transport or metabolic enzymes) that were not inhibited by diazepam. There are no published data regarding the stereoselectivity of metabolism enzymes for methadone in rats. In studies using human microsomes, CYP2B6 preferentially metabolizes $S$-methadone (Totah et al., 2008) and CYP2C19 R-methadone (Gerber et al., 2004), while CYP1A2 was not stereoselective (Eap et al., 1997). Interestingly, CYP3A4 affinity for $R$-methadone was reported to be higher than for $S$-methadone (Foster et al., 1999); however stereoselectivity of CYP3A4-mediated methadone metabolism is still debated (Gerber et al., 2004; Totah et al., 2007; Wang and Devane, 2003).

Increased AUC of methadone concentrations without alterations in its $T_{1 / 2 \beta}$ when pre-treating rats with diazepam supported a diazepam-mediated increase in methadone i.p. bioavailability (Fig. 4). Based on the peak diazepam concentration $(1.76 \mu \mathrm{mol} / \mathrm{L})$ measured after intravenous administration of 1.2 $\mathrm{mg} / \mathrm{kg}$ diazepam in rats (Igari et al., 1982) and assuming that diazepam pharmacokinetics are linear up to $20 \mathrm{mg} / \mathrm{kg}$ with a rapid and complete absorption by the s.c. route, we hypothesize that plasma diazepam concentrations may have reached $\sim 29.4 \mu \mathrm{mol} / \mathrm{L}$ in our study. Compared to diazepam $\mathrm{IC}_{50}(25.02 \mu \mathrm{mol} / \mathrm{L})$, such expected concentrations supported the occurrence of significant CYP inhibition in vivo as reported. Additionally, the diazepam elimination half-life of 24.8 min (Igari et al., 1982) clearly explained why diazepam inhibitory effects on methadone metabolism occurred during its absorption and distribution phases (liver first-pass) rather than its elimination phase.

Here, the diazepam/methadone combination increased the mean peak $R$-methadone concentrations in plasma from 3.4 to $4.9 \mu \mathrm{mol} / \mathrm{L}$. We previously studied $R$-methadone concentrations associated with the half-maximum effects $\left(\mathrm{EC}_{50}\right)$ on $\mathrm{T}_{\mathrm{I}}(1.6 \mu \mathrm{mol} / \mathrm{L}), \mathrm{PaO}_{2}(3.7 \mu \mathrm{mol} / \mathrm{L}), \mathrm{PaCO}_{2}(10.8 \mu \mathrm{mol} / \mathrm{L})$, and $\mathrm{T}_{\mathrm{E}}(15.6$ $\mu \mathrm{mol} / \mathrm{L})($ Chevillard et al., 2010). These data clearly explain why alterations in ventilation resulting from 
the combination of diazepam with $5 \mathrm{mg} / \mathrm{kg}$ methadone were limited to the observed significant increase in $\mathrm{T}_{\mathrm{I}}$. Moreover, diazepam-mediated inhibition of methadone metabolism appears to explain the observed effects on ventilation induced by the diazepam/methadone combination, even though additional mechanisms could not be definitively ruled out, including a pharmacodynamic interaction or the alternative pharmacokinetic interaction on protein binding previously suggested to explain the significant increase in brain and liver diazepam concentrations observed when administering diazepam one hour before intravenous methadone (Liu et al., 1978).

In humans, inter-individual variability makes it impossible to anticipate, with acceptable approximation, the relationship between the dose, blood concentrations, and clinical effects of methadone (Ferrari et al., 2004). Several drugs, including BZDs, may influence CYP3A4, 2B6, 2C19, and 2D6mediated metabolism of methadone, resulting in potential clinical respiratory toxicity (Eap et al., 2001; Foster et al., 1999; Kharasch et al., 2008; Totah et al., 2008). Methadone and diazepam are two competitive CYP3A4 substrates (Ferrari et al., 2004), leading to diazepam-mediated reduction in methadone in vitro metabolism (Iribarne et al., 1997) attributed to diazepam's higher affinity for CYP3A4 (Weschules et al., 2008). However, comparison of diazepam $\mathrm{IC}_{50}$ values $(25 \mu \mathrm{mol} / \mathrm{L})$ with the range of maximum diazepam plasma concentrations $(7.02-8.78 \mu \mathrm{mol} / \mathrm{L})$ that could be achieved seriously questions the clinical pertinence of this inhibition mechanism in vivo (Walker et al., 1998). Interestingly, when combining methadone with various CYP3A4-metabolised BZDs, higher $R$-methadone concentrations were achieved, supporting a mechanism of BZD-mediated competitive inhibition of methadone metabolism in vivo (Hallinan et al., 2009). However, in contrast to these data as well as to our findings in rats, Preston et al. found that concurrent methadone and diazepam administration did not significantly change the time-course or AUC of methadone, diazepam or $\mathrm{N}$-desmethyldiazepam concentrations in plasma in comparison to concentrations measured by the administration of either drug alone (Preston et al., 1986).

In humans, several studies supported potentiating clinical effects with the BZD/methadone combination. BZD users exhibited higher levels of psychopathology and social dysfunction among 
methadone maintenance clients (Drake et al., 1993). Diazepam significantly altered subjective drug responses and psychological performance in methadone-maintained subjects (Farré et al., 1998; Lintzeris et al., 2007). Interestingly, diazepam significantly increased reports of good, like, strong, and high when using methadone, resulting in a decrease in the amount of methadone consumed (Spiga et al., 2001). The diazepam/methadone combination elicited greater alterations in subjective drug effects, psychological performance, and physiologic parameters including pupil diameter and sedation in comparison to those induced by either drug alone (Lintzeris et al., 2007; Preston et al., 1984). However, none of the potentiated effects implicated respiration.

Consistently, although BZDs were hypothesized to play a significant role in methadone-related deaths by increasing upper airway obstruction (Caplehorn and Drummer, 2002), no definitive demonstration has been obtained to date. The rate of BZD detection in methadone-attributed deaths, although variable from one series to another (32\% to $83 \%$ ), was not significantly different from that rate in deaths not attributed to methadone. Nevertheless, in these deaths, detectable levels of methadone were found in contrast to the other prescription opioids like tramadol, codeine, and buprenorphine (Häkkinen et al., 2012; Schields et al., 2007). Fatal poisonings seldom seem to be caused by methadone, although absence of significant differences in methadone concentrations between both groups of patients as reported in forensic studies could be attributed to a multitude of factors, including tolerance, route of intake, associated central sleep apnea, and circumstantial and environmental factors (Corkery et al., 2004). Therefore, the role of BZD co-ingestion in methadone-induced toxicity appears less obvious than with buprenophine, where poisonings and deaths were clearly related to BZD co-ingestion (Mégarbane et al., 2010; Pirnay et al., 2004). However, in methadone-related fatalities, the median concentrations of methadone decreased as the number of co-ingested drugs increased (Häkkinen et al., 2012), suggesting toxicodynamic interactions with the concomitantly used central nervous system depressant drugs.

Our study suffers from a number of limitations: 1)- We studied the diazepam combination with a moderately toxic dose of methadone $\left(30 \%\right.$ of its $\left.\mathrm{LD}_{50}\right)$. Thus, our study does not rule out deleterious interactions with the higher doses that may be encountered in severe overdoses and thus lead to life- 
threatening conditions. Based on the methadone $\mathrm{EC}_{50}$ of $\mathrm{PaCO}_{2}$ increase, we can hypothesize that combining diazepam with higher methadone doses would result in significant respiratory depression in comparison to methadone alone. 2)- From a technical point of view, the reliability of plethysmography in measuring ventilation in awake animals may be questionable for the measurement of $\mathrm{V}_{\mathrm{T}}$ which may be underestimated; however, this technique has been validated against pneumotachography and direct plethysmography with a systemic error on $\mathrm{V}_{\mathrm{T}}$ of $<7 \%$ (Bonora et al., 2004). The more important variability we observed in $\mathrm{V}_{\mathrm{T}}$ measurement in comparison to the other parameters could be also related to various factors that were not taken into account using Bartlett's conventional equation to determine the $\mathrm{V}_{\mathrm{T}}$ (Bartlett and Tenney, 1970; Chaui-Berlinck and Bicudo, 1998). In addition, as significant modification of rat temperature was observed, the results of arterial blood gases were corrected using the actual rat temperatures. We chose not to correct the rat temperatures using heating blankets as this might alter methadone pharmacodynamic effects on related respiratory responses. 3)- Due to the limited sampling time, we were unable to measure methadone pharmacokinetic parameters since the extrapolated AUC represented more than $20 \%$ (27 to 39\%) of the total AUC of the methadone time-course. 4)- We observed a possible enantioselectivity of methadone pharmacokinetics when diazepam was co-administered in rats; however, our experiments could not allow us to definitively conclude about its mechanism.

In conclusion, respiratory effects resulting from the diazepam/methadone combination at elevated doses are limited in comparison to those related to methadone alone despite significant pharmacokinetic interaction in vivo attributed to diazepam-mediated inhibition of methadone metabolism. Although our experimental findings may suggest the relative safety of $\mathrm{BZD} /$ methadone co-prescription, physicians should remain cautious when prescribing BZD in methadone-treated patients like drug addicts, as other underlying conditions may enhance this drug-drug interaction.

\section{References}


Bartlett, D., Tenney, S.M., 1970. Control of breathing in experimental anemia. Respir. Physiol. 10, 384395.

Bonora, M., Bernaudin, J.F., Guernier, C., Brahimi-Horn, M.C., 2004. Ventilatory responses to hypercapnia and hypoxia in conscious cystic fibrosis knockout mice Cftr-/-. Pediatr. Res. 55, 738-746.

Borron, S.W., Monier, C., Risède, P., Baud, F.J., 2002. Flunitrazepam variably alters morphine, buprenorphine, and methadone lethality in the rat. Hum. Exp. Toxicol. 21, 599-605.

Bramness, J.G., Kornør, H., 2007. Benzodiazepine prescription for patients in opioid maintenance treatment in Norway. Drug Alcohol Depend. 90, 203-209.

Caplehorn, J.R., Drummer, O.H., 2002. Fatal methadone toxicity: signs and circumstances, and the role of benzodiazepines. Aust. N. Z. J. Public Health 26, 358-363.

Chaui-Berlinck, J.G., Bicudo, J.E., 1998. The signal in total-body plethysmography: errors due to adiabatic-isothermic difference. Respir. Physiol. 113, 259-270.

Chevillard, L., Mégarbane, B., Risède, P., Baud, F.J., 2009. Characteristics and comparative severity of respiratory response to toxic doses of fentanyl, methadone, morphine, and buprenorphine in rats. Toxicol. Lett. 191, 327-340.

Chevillard, L., Mégarbane, B., Baud, F.J., Risède, P., Declèves, X., Mager, D., Milan, N., Ricordel, I., 2010. Mechanisms of respiratory insufficiency induced by methadone overdose in rats. Addict. Biol. 15, $62-80$.

Cho, A.K., Hiramatsu, M., Distefano, E.W., Chang, A.S., Jenden, D.J., 1990. Stereochemical differences in the metabolism of 3,4-methylenedioxymethamphetamine in vivo and in vitro: a pharmacokinetic analysis. Drug Metab. Dispos. 18, 686-691.

Cicero, T.J., Inciardi, J.A., 2005. Diversion and abuse of methadone prescribed for pain management. JAMA 293, 297-298.

Corkery, J.M., Schifano, F., Ghodse, A.H., Oyefeso, A., 2004. The effects of methadone and its role in fatalities. Hum. Psychopharmacol. 19, 565-576. 
Drake, S., Swift, W., Hall, W., Ross, M., 1993. Drug use, HIV risk-taking and psychosocial correlates of benzodiazepine use among methadone maintenance clients. Drug Alcohol Depend. 34, 67-70.

Eap, C.B., Bertschy, G., Powell, K., Baumann, P., 1997. Fluvoxamine and fluoxetine do not interact in the same way with the metabolism of the enantiomers of methadone. J. Clin. Psychopharmacol. 17, 113-117.

Eap, C.B., Broly, F., Mino, A., Hammig, R., Deglon, J.J., Uehlinger, C., 2001. Cytochrome P450 2D6 genotype and methadone steady-state concentrations. J. Clin. Psycopharmacol. 21, 229-234.

Eap, C.B., Buclin, T., Baumann, P., 2002. Interindividual variability of the clinical pharmacokinetics of methadone: implications for the treatment of opioid dependence. Clin. Pharmacokinet. 41, 1153-1193.

Farré, M., Terán, M.T., Roset, P.N., Mas, M., Torrens, M., Camí, J., 1998. Abuse liability of flunitrazepam among methadone-maintained patients. Psychopharmacology (Berl.) 140, 486-495.

Ferrari, A., Coccia, C.P.R., Bertolini, A., Sternieri, E., 2004. Methadone-metabolism, pharmacokinetics and interaction. Pharmacol. Res. 50, 551-559.

Foster, D.J.R., Somogyi, A.A., Bochner, F. 1999. Methadone N-demethylation in human liver microsomes: lack of stereselectivity and involvement of CYP3A4. Br. J. Clin. Pharmacol. 147, 403-412.

Gerber, J.G., Rhodes, R.J., Gal, J. 2004. Stereoselective metabolism of methadone N-demethylation by cytochrome P4502B6 and 2C19. Chirality 16, 36-44.

Häkkinen, M., Launiainen, T., Vuori, E., Ojanperä, I., 2012. Comparison of fatal poisonings by prescription opioids. Forensic Sci. Int. 222, 327-331.

Hallinan, R., Crettol, S., Agho, K., Attia, J., Besson, J., Croquette-Krokar, M., Hämmig, R., Déglon, J.J., Byrne, A., Ray, J., Somogyi, A.A., Eap, C.B., 2009. Cannabis and benzodiazepines as determinants of methadone trough plasma concentration variability in maintenance treatment: a transnational study. Eur. J. Clin. Pharmacol. 65, 1113-1120.

Igari, Y., Sugiyama, Y., Sawada, Y., Iga, T., Hanano, M., 1982. Tissue distribution of ${ }^{14} \mathrm{C}$-diazepam and its metabolites in rats. Drug Metab. Dispos. 10, 676-679.

Iguchi, M.Y., Handelsman, L., Bickel, W.K., Griffiths, R.R., 1993. Benzodiazepine and sedative use/abuse by methadone maintenance clients. Drug Alcohol Depend. 32, 257-266. 
Iribarne, C., Berthou, F., Baird, S., Dréano, Y., Picart, D., Bail, J.P., Beaune, P., Ménez, J.F. (1996) Involvement of cythochrome P450 3A4 enzyme in the N-demethylation of methadone in human liver microsomes. Chem. Res. Toxicol. 9, 365-373.

Iribarne, C., Dréano, Y., Bardou, L.G., Ménez, J.F., Berthou, F., 1997. Interaction of methadone with substrates of human hepatic cytochrome P450 3A4. Toxicology 117, 13-23.

Jones, J.D., Mogali, S., Comer, S.D., 2012. Polydrug abuse: A review of opioid and benzodiazepine combination use. Drug Alcohol Depend. 125, 8-18.

Kharasch, E., Bedynek, P., Park, S., Whittington, D., Walker, A., Hoffer, C., 2008. Mechanism of ritonavir changes in methadone pharmacokinetics and pharmacodynamics: I. Evidence against CYP3A mediation of methadone clearance. Clin. Pharmacol. Ther. 84, 497-505.

Lintzeris, N., Mitchell, T.B., Bond, A.J., Nestor, L., Strang,, J., 2007. Pharmacodynamics of diazepam coadministered with methadone or buprenorphine under high dose conditions in opioid dependent patients. Drug Alcohol Depend. 91, 187-194.

Lintzeris, N., Nielsen, S., 2009. Benzodiazepines, methadone and buprenorphine: interactions and clinical management. Am. J. Addict. 19, 59-72.

Liu., S.J., Evans, D.B., Wang, R.I., 1978. Correlation of urinary excretion of methadone metabolites with methadone metabolism and analgesia in the rat. J. Pharmacol. Exp. Ther. 204, 67-76.

Lynch, T.A., Meyers, D.B., 1958. A study of the selective antagonism by $\mathrm{N}$-allylnormorphine against meperidine, methadone, and morphine. J. Am. Pharm. Assoc. Am. Pharm. Assoc. (Baltim.) 47, 323-325.

Mattick, R.P., Kimber, J., Breen, C., Davoli, M., 2008. Buprenorphine maintenance versus placebo or methadone maintenance for opioid dependence. Cochrane Database Syst. CD002207.

McCormick, G.Y., White, W.J., Zagon, I.S., Lang, C.M., 1984. Effects of diazepam on the arterial blood gas concentrations and $\mathrm{pH}$ of adults rats acutely and chronically exposed to methadone. J. Pharmacol. Exp. Ther. 230, 353-359. 
Mégarbane, B., Lesguillons, N., Galliot-Guilley, M., Borron, S.W., Trout, H., Declèves, X., Risède, P., Monier, C., Boschi, G., Baud, F.J., 2005. Cerebral and plasma kinetics of a high dose of midazolam and correlations with its respiratory effects in rats. Toxicol. Lett. 159, 22-31.

Mégarbane, B., Buisine, A., Jacobs, F., Résière, D., Chevillard, L., Vicaut, E., Baud, F.J., 2010. Prospective comparative assessment of buprenorphine overdose with heroin and methadone: clinical characteristics and response to antidotal treatment. J. Subst. Abuse Treat. 38, 403-407.

Mitchell, T.B., Dyer, K.R., Newcombe, D., Salter, A., Somogyi, A.A., Bochner, F., White, J.M., 2004. Subjective and physiological responses among racemic-methadone maintenance patients in relation to relative (S)-vs (R)-methadone exposure. Br. J. Clin. Pharmacol. 58, 609-617.

Nielsen, S., Taylor, D.A., 2005. The effect of buprenorphine and benzodiazepines on respiration in the rat. Drug Alcohol Depend. 79, 95-101.

Paulozzi, L.J., 2006. Opioid analgesic involvement in drug abuse deaths in American metropolitan areas. Am. J. Public Health 96, 1755-1757.

Paulozzi, L.J., Logan, J.E., Hall, A.J., McKinstry, E., Kaplan, J.A., Crosby, A.E., 2009. A comparison of drug overdose deaths involving methadone and other opioid analgesics in West Virginia. Addiction 104, 1541-1548.

Pfizer, 2009. Material safety data sheet. Available at: http://www.pfizer.com/files/products/material_safety_data/PZ00145.pdf, Accessed 18 September 2012. Pirnay, S., Borron, S.W., Giudicelli, C.P., Tourneau, J., Baud, F.J., Ricordel, I., 2004. A critical review of the causes of death among post-mortem toxicological investigations: analysis of 34 buprenorphineassociated and 35 methadone-associated deaths. Addiction 99, 978-988.

Pond, S.M., Tong, T.G., Benowitz, N.L., Jacob, P., Rigod, J., 1982. The lack of effect of diazepam on methadone metabolism in methadone-maintained addicts. Clin. Pharmacol. Ther. 31, 139-143.

Preston, K.L., Griffiths, R.R., Stitzer, M.L., Bigelow, G.E., Liebson, I.A., 1984. Diazepam and methadone interactions in methadone maintenance. Clin. Pharmacol. Ther. 36, 534-541. 
Preston, K.L., Griffiths, R.R., Cone, E.J., Darwin, W.D., Gorodetzky, C.W., 1986. Diazepam and methadone blood levels following concurrent administration of diazepam and methadone. Drug Alcohol Depend. 18, 195-202.

Shannon, H.E., Holtzman, S.G., Davis, D.C., 1976. Interactions between narcotic analgesics and benzodiazepine derivatives on behavior in the mouse. J. Pharmacol. Exp. Ther. 199, 389-399.

Shields, L.B.E., Hunsaker III, J.C., Corey, T.S., Ward, M.K., Stewart, D., 2007. Methadone toxicity fatalities: a review of medical examiner cases in a large metropolitan area. J. Forensic Sci. 52, 13891395.

Shook, J.E., Watkins, W.D., Camporesi, E.M., 1990. Differential roles of opioid receptors in respiration, respiratory disease, and opiate-induced respiratory depression. Am. Rev. Respir. Dis. 142, 895-909.

Spaulding, T.C., Minium, L., Kotake, A.N., Takemori, A.E., 1974. The effect of diazepam on the metabolism of methadone by the liver of methadone-dependent rats. Drug Metab. Dispos. 2, 458-463.

Spiga, R., Huang, D.B., Meisch, R.A., Grabowski, J., 2001. Human methadone self-administration: effects of diazepam pretreatment. Exp. Clin. Psychopharmacol. 9, 40-46.

Tallarida, R., Murray, R.B., 1981. Area under a curve: Simpson's rule and trapezoidal rule, in: Tallarida, R., Murray, R.B., (Eds.), Manual of Pharmacologic Calculations with Computer Programs. SpringerVerlag, New York, pp. 47-49.

Totah, R.A., Allen, K.E., Sheffels, P., Whittington, D., Kharasch, E.D., 2007. Enantiomeric Metabolic Interactions and Stereoselective Human Methadone Metabolism. J. Pharmacol. Exp. Ther. 321, 389-399. Totah, R.A., Sheffels, P., Roberts, T., Whittington, D., Thummel, K., Kharasch, E.D., 2008. Role of CYP2B6 in stereoselective human methadone metabolism. Anesthesiology 108, 363-374.

Walker, M.C., Tong, X., Brown, .S, Shorvon, S.D., Patsalos, P.N., 1998. Comparison of single- and repeated-dose pharmacokinetics of diazepam. Epilepsia 39, 283-289.

Wang, J.S., DeVane, C.L., 2003. Involvement of CYP3A4, CYP2C8, and CYP2D6 in the metabolism of (R)- and (S)-methadone in vitro. Drug Metab. Dispos. 31, 742-747. 
Webster, L.R., Cochella, S., Dasgupta, N., Fakata, K.L., Fine, P.G., Fishman, S.M., Grey, T., Johnson, E.M., Lee, L.K., Passik, S.D., Peppin, J., Porucznik, C.A., Ray, A., Schnoll, S.H., Stieg, R.L., Wakeland, W., 2011. An analysis of the root causes for opioid-related overdose deaths in the United States. Pain Med. 12 Suppl. 2, S26-35.

Weschules, D.J., Bain, K.T., Richeimer, S., 2008. Actual and potential drug interactions associated with methadone. Pain Med. 9, 315-344.

White, W.J., Zagon, I.S., 1979. Acute and chronic methadone exposure in adult rats: studies on arterial blood gas concentrations and pH. J. Pharmacol. Exp. Ther. 209, 451-455. 


\section{Figure legends}

Fig. 1. Effects of Tween $20^{\circledR}$ (solvent, black), Tween $20^{\circledR}+5 \mathrm{mg} / \mathrm{kg}$ methadone (MTD, vertical line), 20 $\mathrm{mg} / \mathrm{kg}$ diazepam + $5 \mathrm{mg} / \mathrm{kg}$ methadone (DZP+MTD, white), and $20 \mathrm{mg} / \mathrm{kg}$ diazepam + Tween20 ${ }^{\circledR}(\mathrm{DZP}$, horizontal line) on rat body temperature (A) and sedation (B). Each group consisted of eight rats. Values represent mean \pm S.E.M of the areas under the curve (AUC) for each parameter between the time before injection and 240 min postinjection. Comparisons were performed using ANOVA followed by multiple tests using Bonferroni's correction. Comparisons versus solvent: ${ }^{\# \#} p<0.001$; versus diazepam: *** $p<$ 0.001 ; versus methadone: ${ }^{\S \S} p<0.001$.

Fig. 2. Effects of Tween $20^{\circledR}$ (solvent, black), Tween $20^{\circledR}+5 \mathrm{mg} / \mathrm{kg}$ methadone (MTD, vertical line), 20 $\mathrm{mg} / \mathrm{kg}$ diazepam $+5 \mathrm{mg} / \mathrm{kg}$ methadone (DZP+MTD, white), and $20 \mathrm{mg} / \mathrm{kg}$ diazepam + Tween20 ${ }^{\circledR}(\mathrm{DZP}$, horizontal line) on $\mathrm{PaCO}_{2}, \mathrm{PaO}_{2}$, arterial $\mathrm{pH}$, and bicarbonate concentration. Each group consisted of eight rats. Values represent mean \pm S.E.M of the areas under the curve (AUC) for each parameter between the time before injection and 240 min postinjection. Comparisons were performed using ANOVA followed by multiple tests using Bonferroni’s correction. Comparisons versus solvent: ${ }^{\#} p<0.05$ and ${ }^{\# \#} p<0.01$; versus diazepam: $* p<0.05, * * p<0.01$, and $* * * p<0.001$.

Fig. 3. (A) Effects of Tween $20^{\circledR}$ (solvent, black), Tween $20^{\circledR}+5 \mathrm{mg} / \mathrm{kg}$ methadone (MTD, vertical line), $20 \mathrm{mg} / \mathrm{kg}$ diazepam $+5 \mathrm{mg} / \mathrm{kg}$ methadone (DZP+MTD, white), and $20 \mathrm{mg} / \mathrm{kg}$ diazepam + Tween $20^{\circledR}$ (DZP, horizontal line) on plethysmography parameters (respiratory frequency, inspiratory time, expiratory time, and tidal volume). (B) Effects of Tween $20^{\circledR}$ (solvent, black circles), Tween20 ${ }^{\circledR}+5$ $\mathrm{mg} / \mathrm{kg}$ methadone (MTD, black squares), $20 \mathrm{mg} / \mathrm{kg}$ diazepam $+5 \mathrm{mg} / \mathrm{kg}$ methadone (DZP+MTD, white

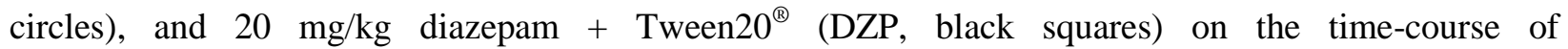
plethysmography parameters. Each group consisted of eight rats. The time-course (A) and areas under the curve (AUC) between the time before injection and $240 \mathrm{~min}$ postinjection (B) for the effects on the 
plethysmography parameters are expressed as mean \pm S.E.M. Comparisons were performed using ANOVA followed by multiple tests using Bonferroni's correction. Comparisons versus solvent: ${ }^{\#} p<$ 0.01 and ${ }^{\# \# \#} p<0.001$; versus diazepam: $* * * p<0.001$; versus methadone: ${ }^{\S} p<0.05,{ }^{\S \S} p<0.01$, and ${ }^{\S \S} p<$ 0.001 .

Fig. 4. Plasma $R$ - and $S$-methadone concentrations in rats treated with Tween $20^{\circledR}+5 \mathrm{mg} / \mathrm{kg}$ methadone (MTD, white squares) or $20 \mathrm{mg} / \mathrm{kg}$ diazepam $+5 \mathrm{mg} / \mathrm{kg}$ methadone (DZP+MTD, black circles). Each group consisted of eight rats. The time-course (A) and areas under the curve (AUC) between the time before injection and 240 min postinjection (B) of methadone concentrations are expressed as mean \pm S.E.M. Comparisons were performed using Mann-Whitney $U$-test.: $* p<0.05,{ }^{* *} p<0.01$, and ${ }^{* * *} p<$ 0.001 .

Fig. 5. Concentration/effect relationships regarding $\mathrm{PaCO}_{2}$ and inspiratory time in rats treated with 5 $\mathrm{mg} / \mathrm{kg}$ methadone (A) and $20 \mathrm{mg} / \mathrm{kg}$ diazepam $+5 \mathrm{mg} / \mathrm{kg}$ methadone (B).

Fig. 6. (A) Disappearance of $R$ - and $S$-methadone enantiomers after $120 \mathrm{~min}$ of incubation with different concentrations of diazepam (DZP) expressed in relative percentage in comparison to the control (diazepam: $0 \mu \mathrm{mol} / \mathrm{L}$ ). (B) Formation of racemic EDDP after 120 min of incubation with different concentrations of diazepam expressed in relative percentage in comparison to the control (diazepam: 0 $\mu \mathrm{mol} / \mathrm{L})$. Values are expressed as mean \pm S.E.M for three independent experiences. Comparisons were performed using one-way ANOVA followed by multiple tests using Dunett's correction. Diazepam 0 $\mu \mathrm{mol} / \mathrm{L}$ versus other diazepam concentrations: $* * p<0.01$ and $* * * p<0.001$. 